ARTICLE HISTORY: Received: September 18, 2021 Accepted: November 12, 2021 Published: November 19, 2021

АКТУАЛЬНЫЕ ПРОБЛЕМЫ НАЛОГООБЛОЖЕНИЯ ИНДИВИДУАЛЬНЫХ ПРЕДПРИНИМАТЕЛЕЙ

\author{
Царбаева Альбина Булатовна \\ Студент - магистрант 3 курса группы 01ЮРв7910 \\ Московский финансово-юридический университет МФЮА
}

\title{
CURRENT PROBLEMS OF TAXATION OF INDIVIDUAL ENTREPRENEURS
}

\author{
Tsarbaeva Albina Bulatovna \\ Student - undergraduate of the 3rd year of group 01YURv7910 \\ Moscow University of Finance and Law MFLA
}

\begin{abstract}
Аннотация. Одна из глобальных проблем для малого бизнеса является налогообложение. Проблема вызвана с существующими противоречиями в налоговом законодательстве и его нестабильностью, а составные налогообложения напрямую зависят от государства и форм собственности, от льгот, представляющиеся тому или иному роду деятельности предприятий малого бизнеса.

В последние годы в России ведется много разговоров об исключительной важности малого бизнеса для развития страны и ее экономики, для формирования «среднего класса» а также для установления социальной и политической стабильности в стране. В статье приведены данные о состояние налогообложении индивидуальных предпринимателей. Особое внимание уделено проблемам, с которыми сталкиваются индивидуальные предприниматели.

Abstract. One of the global challenges for small businesses is taxation. The problem is caused by the existing contradictions in tax legislation and its instability, and the components of taxation directly depend on the state and forms of ownership, on the benefits that are presented to one or another type of activity of small businesses.

In recent years, there has been a lot of talk in Russia about the exceptional importance of small business for the development of the country and its economy, for the formation of a "middle class" as well as for the establishment of social and political stability in the country. The article provides data on the state of taxation of individual entrepreneurs. Particular attention is paid to the problems faced by individual entrepreneurs.

Ключевые слова: налоговое законодательство, налоговая система, налоговый орган, налогообложение, индивидуальный предприниматель, банкротство.

Key words: tax legislation, tax system, tax authority, taxation, individual entrepreneur, bankruptcy.
\end{abstract}

В настоящее время в российской экономике большую роль играет бизнес. Индивидуальные предприниматели, реализовывая свою деятельность, сталкиваются с кругом проблем, которые тормозят их развитие. Зачастую мы можем наблюдать, как введение предпринимательской деятельности связывается с большими рисками, в том числе и налоговыми. В этой главе приведены данные о состояние налогообложении индивидуальных предпринимателей. Особое внимание уделено проблемам, с которыми сталкиваются индивидуальные предприниматели.

Сложная и запутанная система налогообложения, высокое налоговое бремя, нестабильное законодательство, разногласие в нормативно-правовых актах является недостатками в существующей системе налогообложения индивидуальных предпринимателей. Также следует не забывать, что растущий налоговый долг - это прямой путь к банкротству.

В настоящий момент для предпринимателя требуется полное понимание и знание своих обязанностей по уплате налоговых платежей. В России очень сложная система и структура налогов, различные виды налогов, которые схожи между собой на 80-90\% требуют постоянного учета. Налоговая структура требует от субъекта налогообложения профессиональных знаний, либо субъекту налогообложения придется нанимать высокооплачиваемого специалиста по бухгалтерскому учету.

Учитывая несомненный приоритет прав и интересов государства над налогоплательщиками, индивидуальным предпринимателям в определенных случаях тяжело отстоять свои интересы. В России налоговые ставки устанавливаются без достаточного экономического анализа, что негативно сказывается на субъекта налогообложения. Необходимо отметить, что государство в некоторых случаях пытается устранить предпринимателей, которые ничего не делают. Данная ситуация отразилась в поправках к Федеральному Закону от 08.08.2001 N 129-Ф3 (ред. от 31.07.2020) "О государственной регистрации юридических лиц и индивидуальных предпринимателей", в статье 22.4 указаны условия при которых индивидуальный предприниматель может быть принудительно снят с учета Федеральной Налоговой службой, также статья 
говорит о том, что если дождетесь закрытия ИП в одностороннем порядке со стороны ФНС, то потом в течение 3 лет не сможете получить статус ИП.

Таким образом, данная норма закона свидетельствует о сокращении индивидуальных предпринимателей, поскольку за 3 года сфера деятельности меняется, и гражданин может не захотеть повторно приобрести статус предпринимателя.

Недостаточная четкость и обработка нормативно-правовых актов, и частое изменение законодательства затрудняют работу не только индивидуальных предпринимателей, но и саму налоговую службу. У предпринимателей возникает постоянная необходимость «идти в ногу со временем» и узнавать новшества вносимые в области налогообложения. Зачастую на это просто не хватает времени, случается, что, когда предприниматель изучил одни правила и нормы происходит полное изменение или добавление иных норм. В результате чего случается множество ошибок и предпринимателю приходится платить пеню за несвоевременную уплату налога.

Государство усовершенствует налоговую отчетность предпринимателей, она становится все более запутанной. Начинающему предпринимателю приходится сложно с отчетностью и учетом без отсутствия специальных знаний, в результате непонимания предприниматель сталкивается с большими проблемами из-за чего ему приходится платить штрафные санкции, тем самым увеличивая свои расходы.

Не редко мы можем наблюдать ситуацию, когда у предпринимателей появляется неспособность выполнять обязательства по платежам в результате чего происходит банкротство. Одна из основных причин возникновения банкротства является нестабильная финансовая ситуация в стране, она также может привести к повышение безработицы и цен, снижение уровня жизни населения, падение платежеспособного спроса, возникновение дефицита товаров первой необходимости, рост недоверия к государству и социальной напряженности в обществе. Чтобы избежать этого необходимо использовать финансовые резервы на поддержку ключевых отраслей экономики: социально незащищенные слои населения и малого бизнеса.

Безусловно, для решения проблем налогообложения индивидуальных предпринимателей необходимо стабилизировать налоговое законодательство, для того чтобы индивидуальные предприниматели могли четко и ясно понимать все нюансы налогообложения. Усовершенствовать законодательство так, чтобы были соблюдены интересы как государства, так и налогоплательщиков.

Однако, нельзя сказать о том, что налоговое законодательство должно быть застывшем. Оно реформируется сейчас и должен реформироваться дальше. Налоговая система — это неотъемлемое звено экономики, и она должна реформироваться чтобы противостоять кризису.

Государству нужно повышать уровень знаний предпринимателей в сфере налогообложения, особенно это касается начинающих предпринимателей и тех налогоплательщиков, которые живут в отдаленных районах. В селах практически отсутствуют объекты, которые могли бы оповещать людей о принятых законодательных актах, в том числе отсутствует предоставление консультаций в области налогообложения. Все это влияет на развитие деятельности сельских предпринимателей, поэтому государство должно найти способ информирования и консультирования граждан, проживающих в отдаленных районах. Развитие данной сферы должно быть приоритетной целью для государственной политики, и чтобы достичь этой цели, государству необходимо снизить налоговую нагрузку для индивидуальных предпринимателей.

\section{Список литературы}

1. Антаненкова Е. Упрощенная система налогообложения: учебное пособие /Е. Антаненкова - Москва: ИНФРА, 2016. - 156 с.

2. Богданова Е. В. Налоги и налогообложение в Российской Федерации: учебное пособие / Е. В. Богданова. - Москва: Московская финансово-промышленная академия, 2012. - 432 с.

3. Брызгалин А. В. Налоговая оптимизация / А. В. Брызгалин. - Екатеринбург: Налоги и финансовое право, 2014. - 684 с.

4. Барулин С. В. Специальные налоговые режимы: теоретические и организационные основы / С. В. Барулин - Москва: ИНФРА, 2015. - 205 с.

5. Власенкова В.А. Роль налогообложения в развитии субъектов малого и среднего предпринимательства: проблемы и перспективы/В.А Власенкова//Налог.вестн. - 2013. - №2. 3 - 8 с.

6. Смогина И. А. Налогообложение малых предприятий / И. А. Смогина // Право и экономика. - 2012. № 11.74 - 79c. ВРЮ № 9618

7. Федеральный закон от 08.08.2001 N 129-Ф3 "О государственной регистрации юридических лиц и индивидуальных предпринимателей" // C3 РФ. 2001.

8. Zakon.ru // URL: https://zakon.ru/nalogovoe_i_finansovoe_pravo

9. Лайченкова Н.Н. Международный опыт применения стимулов в налоговом праве / Н.Н. Лайченкова, А.В. Клеймиц // Вопросы экономики и права. - 2013. - № 4. 35 - 37c. 
10. Глебова И.С., Садыртдинов Р.Р. Государственное регулирование малого и среднего предпринимательства: Учебное пособие. - Казань: Казанский государственный университет им. В.И. УльяноваЛенина, 2008. С.152.

\section{References}

1. Antanenkova Ye. Uproshchennaya sistema nalogooblozheniya: uchebnoye posobiye /Ye. Antanenkova Moskva: INFRA, 2016. - 156 p.

2. Bogdanova Ye. V. Nalogi i nalogooblozheniye v Rossiyskoy Federatsii: uchebnoye posobiye / Ye. V. Bogdanova. - Moskva: Moskovskaya finansovo-promyshlennaya akademiya, 2012. - $432 \mathrm{p}$. 2014. $-684 \mathrm{p}$.

3. Bryzgalin A. V. Nalogovaya optimizatsiya / A. V. Bryzgalin. - Yekaterinburg: Nalogi i finansovoye pravo,

4. Barulin C. B. Spetsial'nyye nalogovyye rezhimy: teoreticheskiye i organizatsionnyye osnovy / C. B. Barulin Moskva: INFRA, 2015. - 205 p.

5. 5. Vlasenkova V.A. The role of taxation in the development of small and medium-sized businesses: problems and prospects / V.A. Vlasenkova // Nalog.vestn. - 2013. - №2. $3-8$ p.

6. Smogina I. A. Taxation of small enterprises / I. A. Smogina // Pravo i ekonomika. - 2012. - № 11. $74-79$ p. VRYu № 9618

7. Federal Law of 08.08.2001 N 129-FZ "On state registration of legal entities and individual entrepreneurs" // SZ RF. 2001.

8. Zakon.ru // URL: https://zakon.ru/nalogovoe_i_finansovoe_pravo

9. Laichenkova N.N. International experience of using incentives in tax law / N.N. Laichenkova, A.V. Brandy // Voprosy ekonomiki i prava. - 2013. - № 4. 35 - 37p.

10. Glebova I.S., Sadyrtdinov R.R. Gosudarstvennoye regulirovaniye malogo i srednego predprinimatel'stva: Uchebnoye posobiye. - Kazan': Kazanskiy gosudarstvennyy universitet im. V.I. Ul'yanova-Lenina, 2008. p.152. 